\title{
The Role of Personalized Integrated Educational Systems in the Information-Age Paradigm of Education
}

\author{
Sinem Aslan \\ Yeol Huh \\ Dabae Lee \\ Charles M. Reigeluth \\ Indiana University, United States
}

\begin{abstract}
Aslan and Reigeluth (2011) described a possible future period of educational computing as a "Personalized Computing Period" (p. 12). They described a potential educational technology system, PIES (Personalized Integrated Educational System), to support student learning in this period of educational computing, based on the major and secondary functions proposed by Reigeluth, Watson, Watson, Dutta, Chen, and Powell (2008) for the information-age paradigm of education. Major functions include record keeping for, planning for, instruction for, and assessment for/of student learning. Secondary functions include communication, general student data, school personnel information, and technology administration. In this qualitative research study, seven classroom teachers and one technology coordinator from three high schools were interviewed to reveal how they used their current technology systems with respect to the functions described by Reigeluth et al. (2008). The results revealed that there were discrepancies between the participants' current use of the systems and the ideal use for the information-age paradigm of education. Based on the results, recommendations are offered to teachers, policy makers and technology system designers for better meeting students' information-age educational needs.
\end{abstract}

Keywords: Information-age learning paradigm; Personalized integrated educational system (PIES); Learning management system (LMS); Functions of technology

\section{Introduction}

A shift from the industrial age to the information age has occurred (Toffler, 1980, 1990) and has changed our social and economic lives more than we may have realized. Accordingly, the educational needs and expectations of students are very different than they were before (Duffy, 2009). Consequently, the responsibilities and roles of teachers must also change dramatically. Changes in the needs and roles of students and teachers require changes in the supportive technologies that they use. According to Gilhooly (2001) and Watson, Lee and Reigeluth (2007), recent developments in educational technology can help meet these needs in the information-age paradigm of education. 
The information-age paradigm of education, which is currently implemented in very few schools, has a number of defining characteristics. First, it requires criterion-referenced assessment, which involves an assessment of student learning compared to what the student should attain or be able to handle with regards to the learning objectives (Knight, 2001), instead of ranking, ordering and comparing individuals with their classmates, which is an industrial-age practice (Smith, 1973). In addition, attainment-based student progress is essential in an information-age learning environment. According to Reigeluth (1995), achievement needs to be a "constant" at the competency level, but time should vary based on the progression of each individual student. Based on Bloom's Theory of Mastery Learning (Bloom, 1968; Davis \& Sorrell, 1995), this competencybased progression accommodates students' different paces of learning.

In addition, customized learning is another important characteristic of the information-age paradigm of education. In order to customize students' learning, data need to be kept about an individual student's goals, objectives, characteristics, and attainments mastered. In learning contexts that utilize customized learning, each student will have a number of individualized attainments that need to be met. Since students have different interests, attainments, learning styles, and paces of learning, the role of the teacher needs to adapt in order to accommodate the new learner needs. In customized learning contexts, instead of being the source of information and content, the teacher is responsible for coaching and facilitating individual students' learning based on their personal learning plans in the information-age paradigm of education (Reigeluth, 1995).

Thomas (2000) promotes project-based learning as a way of creating a realistic, constructivist environment in which students are actively involved in an authentic learning environment and intrinsically motivated. Therefore, project-based learning can be utilized in the classroom to help students attain individualized objectives by working on projects that are aligned with their personal learning plans. The teacher plays a role of facilitating and coaching students' learning, rather than a role of content delivery.

\section{Theoretical Framework}

What functions should a technology system perform in order to meet learners' needs and accommodate these changes in the emerging information-age paradigm of education? According to Reigeluth et al. (2008), administrators, teachers, and students need a system that can facilitate and enhance four major information-age functions for student learning: Record keeping, planning, instruction, and assessment. The system also needs to perform several secondary functions, such

as communication, handling of general student data, handling of school personnel information, and technology administration (Reigeluth et al., 2008). These functions and their sub-functions are highlighted in Table 1. 
Table 1. Four Major Functions and Secondary Functions of an Information-Age PIES Proposed by Reigeluth et al. (2008)

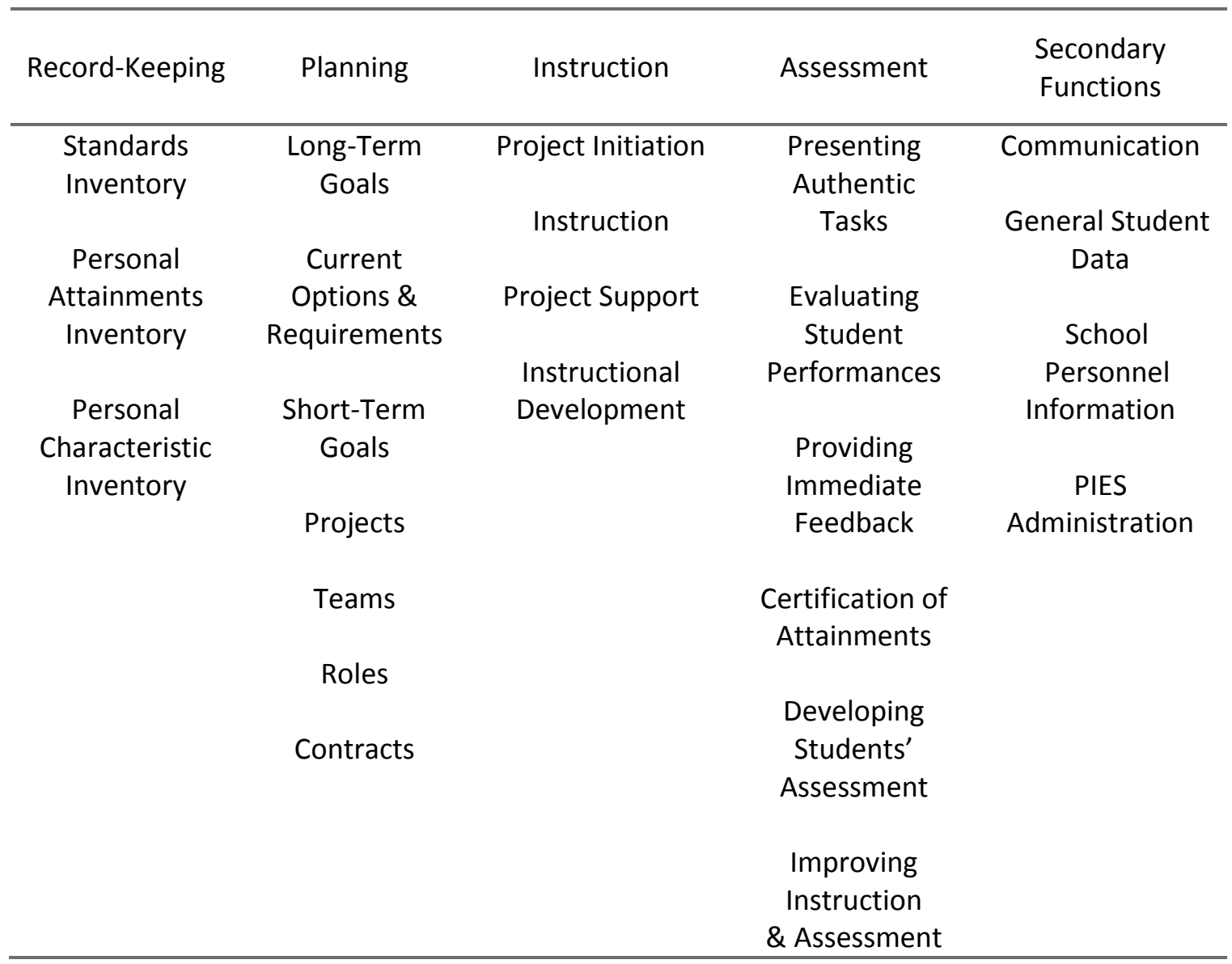

Watson et al. (2007) pointed out that the information-age paradigm of education requires a computer system that has built-in components to support all of the information-age functions mentioned above. While the term Learning Management System (LMS) was initially used for this kind of information-age system, it was often confused with Course Management Systems (CMS) and Integrated Learning Systems (ILS), so the term Personalized Integrated Educational System (PIES) was adopted.

\section{Four Major Functions of PIES}

Record Keeping. In the new paradigm of education, one of the most important functions is to keep a record of what each student has mastered. Current report cards only serve as tools for sorting students. Moreover, they do not indicate what a student has actually achieved. The recordkeeping function has a number of sub-functions: (a) a standards inventory, which identifies and maps all the required standards and many optional standards in all domains for each student, (b) $a$ personal attainments inventory, which portrays the standards each student has mastered, and (c) a personal characteristics inventory, which identifies each student's learning style and profiles 
their multiple intelligences, interests, major life events, and anything else that is useful for improving the learning experience for a student.

Planning. Based on the data in the record-keeping function, decisions should be made to plan for student learning. The planning function of PIES has many sub-functions that (a) help students, parents, and teachers to set long-term goals; (b) determine current learning options that will help students to achieve their long-term goals; (c) pick some of the current options and set them as short-term goals; (d) identify projects for achieving the short-term goals; (e) set project teams, given students' project selections; ( $f$ ) decide on the roles that the teacher, parents, and others will play in supporting the student's learning in the projects, and (g) develop a contract that identifies goals, projects, teams, roles, deadlines, and milestones.

Instruction. The instruction function of PIES helps students and teachers to (a) initiate each project, (b) provide resources/tools/guidance for instruction, (c) provide project support by monitoring and managing the project teams, and (d) guide teachers for developing new instruction. These subfunctions provide customized and learner-centered instruction that maximizes student learning.

Assessment. Teaching and testing are fully integrated within the new paradigm. The sub-functions help teachers to (a) present authentic tasks for student assessment; (b) evaluate student performances based on those tasks, (c) generate immediate feedback on student performances, (d) provide certification when an attainment is met, (e) develop student assessments such as rubrics and tests, and (f) improve instruction and assessments based on their effectiveness.

\section{Four Secondary Functions of PIES}

There are also some secondary functions of PIES that are not directly related to student learning but can nonetheless play an important role in facilitating student learning. (1) The communication function involves teacher communication and collaboration with other teachers, students' parents, and students. It also allows students to communicate and collaborate with each other to facilitate their learning, which is included in one of the major functions, instruction. Thus, different kinds of communication are either major or secondary functions. (2) The general student data function provides access to such data as the student's name, address, birth date, parent/guardian information, health information, attendance, the student's mentor and other teachers, records of major life events, the school or learning community to which the student belongs, the student's homeroom, and community organizations the student is involved. (3) The school personnel information function provides access to such information as a staff member's name and home address, their assigned students, the certifications and awards they have received, their professional development plan and progress, and the teacher's physical location. (4) The PIES administration function oversees the whole system, including managing access to sensitive information about students and staff.

Given these major and secondary functions that support an information-age educational system, questions arise about the extent to which existing technological tools, such as Moodle, can currently serve these functions and the extent to which teachers take advantage of any such capabilities, given that most schools still operate within the industrial-age paradigm. The question 
also arises as to what teachers, policy makers, and designers of technological systems for education can do to advance the use of PIES so that they may better meet students' needs in the information-age paradigm of education.

\section{Research Questions}

This study investigated two major research questions:

1. Which of PIES' four major information-age functions (record keeping, planning, instruction, and assessment) and secondary functions are utilized by teachers in the technology system that teachers currently use to foster student learning?

2. How could teachers, policy makers, and technology system designers advance the design and use of current technology systems in to better meet the needs of the information-age paradigm of education?

\section{Methodology}

\section{Research Context and Design}

This research study was a qualitative case-study with semi-structured interviews. It took place in three high schools, which we will call High School A, High School B, and High School C. All three schools are located in a relatively homogeneous small city in the Midwestern United States. The school district had approximately 10,000 students attending elementary, middle, and high schools. We identified three high schools in which teachers used technology systems relatively actively. At the time of this study (2008-09), High School A had 1,622 students and High School B had 1,733 students. High School C opened in 2008 with 96 students in ninth grade and plans to increase one grade level each year until it includes all four grades of high school. Technology use and resources varied across the three high schools. For instance, the curriculum in High School $C$ was highly technology-focused and team-project oriented compared to the other two schools.

In these high schools, Moodle was the predominant technology system used to foster student learning. Therefore, the features and use of Moodle were investigated for this study, but another system, Skyward, was also investigated. Moodle is a free system that utilizes an open-source architecture. It can be used for developing, managing, and utilizing learning sites for students' learning. It has a flexible interface, which allows teachers to customize it in order to meet their classes' needs. Skyward is a proprietary system used only for administrative issues, such as storing and managing data related to student management. It is widely used in K-12 settings and is currently used in more than 1,300 school districts worldwide (Skyward, n.d.). 


\section{Participants}

The purposive sampling technique was used to select the participants from the three high schools. The criterion for selection of these participants was a high level of usage of Moodle to support student learning. It is important to emphasize that in the schools, there was a limited number of teachers who used Moodle for teaching and learning activities.

A preliminary interview was conducted with the technology coordinator, who was responsible for managing Moodle in all three schools, in order to identify the teachers who met this criterion, as well as to obtain a general understanding of how teachers used Moodle in the school district. The technology coordinator identified eight classroom teachers from different subject areas and grade levels who had incorporated Moodle the most for teaching and learning activities in these schools. This method of selection of these teachers helped us to recruit "the most productive sample" (Marshall, 1996, p. 523) for the study.

While we would have liked to have more participants, these participants represent all who met the criterion in this school district's high schools, and they provided a sufficient number for triangulation of the results. Invitational e-mails were sent to all eight teachers, and seven of them, in addition to the technology coordinator, agreed to participate in this study. Table 2 outlines general information about these participants, their schools, and the subject areas they taught.

Table 2. Research Participants, School, and Subject Area Information

\begin{tabular}{ccc}
\hline Participant pseudonyms & $\begin{array}{c}\text { High school } \\
\text { pseudonyms }\end{array}$ & Role or Subject Area(s) \\
\hline Cody (Male) & - & Technology Coordinator \\
Amber (Female) & A & Math Teacher \\
Laurie (Female) & J & Langanese \& English as a New \\
Joshua (Male) & A & Math Teacher \\
Michael (Male) & B & Math Teacher \\
Clint (Male) & B & Language Arts \\
Jake (Male) & C & American History Teacher \\
Angela (Female) & C & Software Technology and Careers \\
\hline
\end{tabular}

\section{Data Sources/Data Instruments}

Data were gathered from the seven classroom teachers and one technology coordinator through interviews that were semi-structured and open-ended. The interviews with each of the participants lasted about an hour to an hour and half. All of the interviews were audio recorded and transcribed verbatim. The interview questions (see Appendix A) focused on gathering data about how teachers were using their technology systems, such as Moodle and Skyward, and whether these uses were aligned with the major and secondary functions of an information-age PIES. In addition, the interviews asked for suggestions for improving their current educational technology systems. For member checking, seven of the eight participants reviewed the 
transcripts of their interviews via e-mail correspondences. The eighth participant was out of contact and did not review the interview transcript.

\section{Data Analysis}

The primary data analysis method was content analysis. The coding sheet (see Appendix B) was prepared according to the theoretical framework of the PIES functions. Three researchers coded the transcribed data for all eight interviews independently, using separate coding sheets for each interview in order to check inter-rater reliability. After completing the individual coding, the three researchers discussed their results to reconcile their differences and created a final coding sheet. Using this final coding sheet, the researchers analyzed the data and identified the emerging themes.

\section{Findings}

In this section, we present the findings related to the research questions. First, findings for the major and secondary functions of PIES are described in order to illustrate the results related to the first research question. Findings related to the second research question are presented and discussed in the next section. Based on the findings related to the second research question, suggestions are made for teachers, policy makers, and technology system designers in order to advance their current technology systems so that they may better meet students' needs within the information-age paradigm of education.

\section{First Research Question Findings: Major Functions of PIES}

\section{Record Keeping for Student Learning}

Record keeping includes three sub-functions: A standards inventory, a personal attainments inventory, and a personal characteristic inventory. Results show that none of the seven teachers utilized Moodle to keep track of available standards, individual attainments, or personal characteristics. Laurie, a teacher of Japanese and ENL, described record keeping for her class:

At the beginning of the semester, I used to post questions about their background or interests and get answers from them. But I could not find a good way to download the information into useable format from Moodle into a spreadsheet, so now I do not really do that. (Laurie, April 2009)

All seven teachers used Skyward to maintain students' grades because Skyward was tailored to the schools' learning outcomes, and its use was encouraged in the schools for attendance and grade reporting issues. However, the use of Skyward was not aligned with PIES' functions because it did not keep track of students' individual attainments. Teachers used Skyward to enter grades so that students and parents could view them. 
These findings generally illustrate that Skyward's record-keeping function facilitates mostly data administration, rather than student learning, which is not aligned with the information-age recordkeeping functions of PIES. Moodle was not used at all for the record-keeping function of PIES.

\section{Planning for Student Learning}

The planning function of PIES entails creating and storing a customized learning plan for each individual student. There was no evidence that Moodle was being utilized for such planning. Two teachers out of the seven suggested that there were two major factors that constrained such use.

The first constraining factor was that the standardized education system discourages teachers from setting individualized learning goals. Angela stated, "The goals are school-wide. Therefore, I cannot say I have a specific goal for each of the kids." (April 2009). The second constraining factor was that teachers had not found any functions they could utilize for planning in Moodle or had not figured out how to use these functions. Angela said, "Moodle does not provide any help for setting these goals" (April 2009). Jake also stated:

From the planning standpoint, Moodle doesn't provide any functions which are directly related to that. There is a tool called Target that lets you set specific learning goals for individual students and give them feedback, but I don't know really how to run this. I've got to learn this. (Jake, April 2009)

Instead of setting individual goals, one of the teachers, Laurie, set goals for small groups of two to four students. She grouped the students using the Choice function in Moodle, and based on the abilities and interests of group members, she set a specific group goal and provided them with group-specific content.

Jake, another teacher who used project-based collaborative learning, also used the Choice function to group students. However, he had project-specific objectives, rather than group-specific ones. Another function Jake used was the Journal function, in which a student sets his or her own goals at the beginning and reflects on his or her performance at the end. However, he placed a greater emphasis on reflection than on planning or setting individual goals. Two of the teachers had used Moodle to provide the class with an agenda using the Calendar function. Jake stated, "We put up a simple agenda that we are going through. Students can check the agenda to see what to do next using the calendar." (April 2009).

Although some of the teachers set learning goals and plans for their students' learning, Moodle was not used effectively by the teachers for this function of PIES.

\section{Instruction for Student Learning}

The third function of PIES is instruction. The instruction function includes four sub-categories: Project initiation, instruction, project support, and instructional development. Overall, we found that all of the seven teachers had used the instruction function. 
For the first sub-function, project initiation, two of the seven teachers used Moodle. Laurie described how she used it: "Based on the ability or interest of students, I group them and give them group-specific content." (April 2009).

Instruction, the second sub-function, was the most popular one. All seven teachers mentioned that they were using it with Moodle, but the types of their usage were slightly limited. All seven teachers mentioned that they had used Moodle for sharing resources and information related to the instruction. For instance, Michael, a math teacher, explained:

The students can go in and do the quizzes and get the worksheets and other extra stuff whenever they want. I prepared some links that the students can access the resources such as geometry stuff. If the students need extra practice, they can go to Moodle and find the resources. (Michael, April 2009)

Angela added "... I generate lesson plans and upload them into Moodle, giving some instruction to kids.... I do presentations and upload them to Moodle." (April 2009). Amber, another math teacher, also noted that she posted notes and scanned and uploaded worksheets for every class. In addition, she used Moodle to upload some guidelines, references, and assignments.

Besides sharing resources, four teachers stated that they used the discussion forum feature for instruction. Joshua said:

Any students can upload something. They upload something funny sometimes. They do forum online, and they understand how to post pictures. That is an unintended side effect, but it helps to build a pretty good relationship with students and me and among students, socializing with each other. (Joshua, April 2009)

Jake also mentioned:

We use the forum tool fairly regularly, depending on the assignment. You need to answer the question, sometimes for debate, share, and challenge each other's ideas, and resources pages. If you find good resources, you can post them. Or if you have questions or problems, you can post there. Anybody can answer the questions. One thing that I played with a little bit is that the group could have their own forum so that they can have personal discussions. (Jake, April 2009)

Although all of the teachers interviewed used Moodle for the instruction sub-function, a few teachers decided not to use its discussion feature for instruction. Amber said, "I tried, but it did not go well. They used it as another form of socializing with others, rather than for school work."(April 2009). In addition, Angela also mentioned:

Since I have freshman students, discussion boards are not suitable for them, since they do not have the maturity to regulate their comments. However, Moodle has the capability of having discussion boards. If I have upper classes, I will use this feature a lot more. (Angela, April 2009) 
Angela claimed that there was no actual instruction sub-function in Moodle. She did not consider providing documents and discussions to be actual instruction. Other than the discussion feature, Clint tried the audio feature and saw its capabilities, even though he did not utilize this feature in his classes. Jake also used the glossary feature and said, "There is a glossary feature. The neat thing about it is we can put in the word and definition, and they hover when we have the word in Moodle." (April 2009).

Some of the interviewed teachers, such as Joshua, used Moodle to give feedback to his students. He used Moodle to check his students' degree of involvement in assignments. He stated that:

Within Moodle, I use the communication feature. I tell them I will check Moodle every night, and give feedback, and give positive reinforcement in class, saying like, 'Hey, David, I saw you put comments on Moodle. Thanks'... (Joshua, April 2009)

Moreover, Jack also used Moodle to give his students feedback. He looked at students' submissions and wrote students' grades and his comments in Moodle so that the students could see them.

In addition to giving feedback with Moodle, Joshua mentioned that he tried to be online and check whether students had posted any questions related to the assignments so that he could reply to them.

Evidence of using Moodle for the other two sub-categories of instruction, project support and instructional development, was rarely found in the interviews. Only Jake cited his use of Moodle for project support, saying:

We put up a simple agenda that we are going through. Students can check the agenda to see what to do next using the calendar. Using the calendar, they can have clear class expectations and do more self-management. All of the different projects are in Moodle, including entry documents, rubric, project-resources, so that students can understand the scope of the project. (Jake, April 2009)

In contrast to the record keeping and planning functions, the findings illustrate that interviewed teachers did use some of the instruction features of their technology systems, such as discussion forms, in accordance with the information-age functions of PIES. However, the level of integration and use of these features were minimal.

\section{Assessment for and of Student Learning}

The information-age assessment sub-functions include presenting authentic tasks, evaluating student performances, providing immediate feedback, certifying attainments, developing students' assessment and improving instruction and assessment. Three teachers used the quiz function to assess students' knowledge for formative evaluation of both students and instruction. 
Laurie and Michael created a quiz in Moodle that provided immediate feedback to students, and then utilized the results to improve their instruction. Jake created a pretest and left it open throughout the semester so that the students could continuously self-assess their knowledge of the content. He also improved his test items based on the test item analysis function in Moodle, which provided the discrimination coefficient (though this is only used for norm-referenced assessment).

However, none of the teachers interviewed used Moodle for summative evaluation. Joshua stated, "I am not using test functions yet.... Teachers use Moodle for sharing information and helping students, not creating quizzes yet." (April 2009). However, he suggested the possibility of using the pretest feature in Moodle and using the pretest results to customize his instruction, stating, "I will be able to customize my instructional content based on the results of the pretest. I can make a decision of what I am going to skip or focus on." (Joshua, April 2009).

Other teachers were hesitant to use the test feature because they perceived it as time consuming. Clint stated, "I love the test feature, but it takes too long to prepare, so I have not used the test feature of Moodle" (April 2009). Amber, a math teacher, also pointed out that typing mathematical codes takes significantly more time than doing it by hand, and it would be time consuming not only for her as a teacher, but also for her students. For this reason, she was reluctant to use the Moodle test function. Finally, Laurie described some use of a Moodle feature for instructional evaluation. She improved her instruction based on an evaluation of chats among students.

Based on these findings, although some of the teachers stated they used the quiz function in Moodle for formative assessment of students' knowledge, they used norm-referenced assessment, which is an industrial-age practice and inconsistent with the information-age functions of PIES.

\section{First Research Question Findings - Secondary Functions of PIES}

As identified by Reigeluth et al. (2008), the secondary functions of PIES are the ones that do not directly focus on student learning. These secondary functions include communication, general student data, school personnel information, and PIES administration. This section of the findings will describe the use of each secondary function by the interviewed teachers.

\section{Communication}

In a learner-centered environment, communication is an important secondary function, since it provides teachers with means of communicating and collaborating with other teachers and staff, students, students' parents, and other members of the community (Reigeluth et al., 2008). This communication function helps students communicate with each other and with their teachers. This function also helps parents check their child's performance. Those communications that directly influence student learning belong under the instruction function, described earlier. 
Communication with Parents and Students. The results demonstrate that the teachers who were interviewed used a number of familiar tools instead of using Moodle. For instance, use of Skyward for communications was predominant among the teachers interviewed in the three schools. The teachers used Skyward, rather than Moodle, to communicate with parents and students via announcements. The school district's technology coordinator, Cody, mentioned that the schools had invested a great deal in Skyward and explained the use of Skyward as follows:

There is also a grade book [in Skyward], and it is also used for what is called student family access. So students have an account and log in to that particular system to see their grades, to see announcements that their teacher may have posted on its calendar, and parents also have access to that with a different user name and password, which gives them the student's grade and announcements, as well as one's account balances and things like this. (Cody, April 2009)

In addition to this one-way communication for grades and announcements, teachers also used a number of different technologies to communicate with students, parents, and other teachers. Although Moodle has functionality for sending and receiving messages, the teachers interviewed preferred to use other e-mail hosting services. Cody, Clint, Angela, and Joshua pointed out that they used different listservs to communicate with other teachers, students, and parents. Joshua explained one of the major reasons as: "If parents have questions, they will email or phone. It might be an age gap, too. I don't know how parents will be comfortable with that. They might be intimidated." (April 2009).

Use of Asynchronous Chat to Communicate with Students Instead of Instant Messaging. Some of the interviewed teachers used the asynchronous chat function of Moodle to communicate with their students about the assignments. For instance, Joshua mentioned that he used this asynchronous chat function to answer students' questions about the assignments. However, he emphasized that he had not yet used instant messaging. Although Joshua had not yet used the instant messaging function, he thought that it might be interesting to use. However, the English teacher, Jake, believed that, since he was not giving an online class, instant chat would not be useful for him.

No Use of Moodle for Communication among Teachers. Though teachers' online communication and collaboration are very important factors for the professional development of the teachers, the technology coordinator, Cody, pointed out that they were not using Moodle for this purpose. However, he stated that in the near future, they would begin to work on this. Cody mentioned that:

I am anticipating because the principal of the building [High School A] has said that next school year, because of some changes in some of the instructional structure in the building, we would be using Moodle particularly for threaded discussion for teachers to participate in that sort of activity about the upcoming changes or during the changes while they are going on to make sure that we try to stay up with the rest of their concerns and issues and look for resolutions. For the faculty in particular next year, I think it will be used in that way. (Cody, April 2009) 
These findings show that the teachers we interviewed preferred to use tools other than Moodle to communicate with other teachers, students, and parents. In addition, some of the teachers used asynchronous chat to communicate with their students, rather than using instant messaging. Assignment-related communications, such as giving positive reinforcement and feedback, were common uses described by the interviewed teachers. However, communication via Moodle among teachers was not observed in the interviewed teachers.

\section{General Student Data}

General student data handling is another secondary function of PIES. The technology coordinator, Cody, stated that in these three high schools, Moodle was used to record each of the students' information to the database, such as name, addresses, contact information, etc. However, this information did not include such information-age components as records of major life events, the school or learning community to which the student belongs, the student's homeroom, or community organizations with which the student is involved. In these three high schools, students' records were initiated at the beginning of each school year, but they remained static during the school year.

Some of the teachers collected individual students' information in order to better identify students' personal needs. For example, Laurie posted some questions to Moodle related to the students' backgrounds and interests so that students could post their answers back. This information helped Laurie better understand her students' personal needs. However, this information was not stored in a database. Therefore, this use is not aligned with the informationage functions of PIES. It can be concluded that the interviewed teachers did not keep general student data in accordance with the learner-centered paradigm.

\section{School Personnel Information}

Some school personnel information was kept, but only for documentation. For example, Skyward was being used as a data management system to enter school personnel information. The technology coordinator, Cody, stated that in Skyward, there was a personnel section that kept track of all employee records, including financial documentation. However, he mentioned that these records might be kept for back-up purposes and that administrators with higher-level access privileges have access to such school personnel information.

\section{PIES Administration}

A major aspect of PIES administration is confidentiality. Sensitive data, such as medical records and social security numbers, are kept in this system. Students and parents should have some control over how much of their information is made public, and to whom it is made public (Reigeluth et al., 2008). Cody, the technology coordinator, stated that they had over 2,900 Moodle user records. However, they did not keep a backup of Moodle data, which represented a flaw both in terms of security and in terms of the maintenance of sensitive data. In addition, in some cases, 
such as for graduating students, the technology coordinator had to manually delete student records, since there was not an automated record-keeping feature in Moodle. Some teachers also mentioned that, since Moodle had its own password-protected system, this feature actually helped teachers use copyrighted resources more easily. In contrast, Cody pointed out that lack of creating secure passwords was an issue when they first started using Moodle in the schools.

These findings show that, although sensitive data were kept in Moodle, the system had some flaws in terms of secure and confidential data management.

\section{Second Research Question Findings}

In addition to the findings related to the use of information-age functions of PIES by classroom teachers, we collected data about ways that teachers, policy makers, and technology system designers can advance their technology systems related to the information-age functions. These data concern the discrepancy between the current uses of Moodle and PIES, the use of different systems for different tasks, and the different uses of PIES for different subject areas. After describing these findings, suggestions are made to teachers, policy makers, and technology system designers of technology systems.

\section{Gap between the Current Use of Moodle and the Information-Age Functions of PIES}

There was strong evidence of a large discrepancy between the current use of Moodle and the ideal use of PIES' functions. Most of the teachers had standardized instruction and assessments and used Moodle to share resources, post class information, and keep records of students' grades. The current use of Moodle better aligns with the industrial-age paradigm than with the information-age paradigm of education. The discrepancy can be attributed to the fact that few schools have shifted to the new paradigm in the USA.

The industrial-age paradigm prevented the teachers from adopting attainment-based assessments or customized instruction. Therefore, it is unsurprising that the teachers' uses of Moodle did not align with the ideal use of PIES in the information age. In this regard, a follow-up study could examine teachers' perceptions of the new educational paradigm and identify barriers that prevent teachers from moving toward this new paradigm. A follow-up study could also investigate the schools that successfully made the transition to the information-age paradigm in order to see what their technology systems look like and how they are using them.

Even though this study revealed that Moodle was not being used as envisioned for the information age, it showed that some functions that had been envisioned for PIES were being utilized. For example, some of the teachers used the Quiz function to let students self-assess their knowledge. In PIES, students are envisioned as self-assessing as much as they want and whenever they want in a place called the "instructional space" (Reigeluth et al., 2008). Additionally, self-regulation is an important feature of the new educational paradigm (Collins \& Halverson, 2009). 


\section{Use of Different Technologies for Different Tasks (E-mail, Skyward, Moodle)}

Most current technology systems have a number of integrated components including chatting, messaging, e-mailing, and record-keeping via a grade book. Moodle, which was the predominant system in the investigated school district, made many of these functions available to teachers. However, the interviewed teachers preferred to use different technologies and tools to perform different tasks. There are underlying reasons for their choice to use a variety of technologies, rather than just Moodle, to accomplish all of their activities.

One of the reasons, mentioned by most of the interviewed teachers, was the schools' policies. For example, in High School C, Skyward was the tool that was used for grade-book tasks. Angela, a teacher in this school, pointed out that they were using Skyward due to school policy, since it was set up based on their school's learning outcomes. Use of Skyward as a grade-book tool was also done in High School B. Michael, a math teacher at High School B, emphasized that school administrators wanted the teachers to use Skyward instead of Moodle.

The second reason for using different technologies is that interviewed teachers preferred to use tools with which they felt comfortable. Moreover, these teachers also pointed out that the students' parents also used the tools with which they felt most comfortable, rather than Moodle. Although Moodle had built-in emailing and messaging functions, most of the teachers interviewed preferred to use their regular email applications instead of Moodle's. Clint, a teacher at High School B, and Joshua, a teacher at High School A, used email applications or the telephone to communicate with parents. Joshua believed that parents did not use Moodle to communicate because of their age or because they might have felt intimated by the tool.

One of the teachers, Michael, stated that he did not want to rely on only one tool, but instead wanted to use a variety of tools to achieve different tasks. Like Michael, Angela also wanted to use a variety of different tools. She used wikis and blogs to facilitate students' learning. However, teachers might prefer an integrated technology system having all of the information-age functions and open source architecture because of the quick accessibility and interoperability of such a system. This possibility needs to be explored further.

\section{Different Uses of PIES for Different Subject Areas}

We found that the interviewed teachers used Moodle differently in different subject areas. The most prevalent use of Moodle was by the teacher who taught American history. He used some features of Moodle that teachers of other subjects also used, such as uploading documents and resources for students to access, use, and share with each other whenever they wanted. However, he utilized the testing and discussion forum features more often. Since his class was based on team projects and covered topics about American history, a number of discussions among group members and across groups were valuable, and he found the discussion forum feature worked very effectively.

Laurie mentioned that she found the chat feature useful and used it often in her class. She had her students practice what they had learned and improve their writing ability at the same time with 
the chat feature. Since she could monitor every chat session, she could give her students immediate feedback if they made a mistake. Just like American history, teaching and learning Japanese also requires communication activities, so the teachers of these subjects frequently utilized features related to communication in their instruction.

However, teachers of math and technology found that the discussion forum and chat features were not always successful and could even be distracting. One math teacher attempted to use the discussion forum, but it turned out that the students used it for socializing, making comments unrelated to the class. Other than communication features, both math teachers interviewed for this study attempted to use other common features, such as the test feature. However, they realized the feature was limiting since they could only make multiple choice-based tests without the help of another program to type math symbols. It was quite time consuming for teachers to prepare and for students to take the test; moreover, students found it difficult to see and type math equations on the computer screen. Thus, math teachers used only basic features of Moodle, such as uploading assignments and sharing resources.

The level of use of Moodle varied across different subjects, and there was a need to develop new features that could meet various needs across different subject areas. For example, Moodle had major limitations for typing math equations or math symbols. Thus, the math teachers had to rely on additional software, such as MathType, to create a math document in a Microsoft Word program, and then upload the Word document to Moodle. The teachers considered this task extremely time consuming, and this was the major reason that the interviewed math teachers did not use Moodle as much as they had originally intended to. Therefore, a new feature that allows users to type math equations or symbols directly within Moodle would greatly facilitate the use of Moodle for the math subject area.

This finding implies that there should be communications among teachers and between teachers and technology system designers regarding specific features for different subject areas. One way of accomplishing this can be to hold regular focus group sessions between teachers and technology system designers, or to have a community of teachers who use Moodle talk about and share their needs and ideas for new features.

\section{Suggestions for Practice}

Based on the review of the literature, our major findings, and taking additional issues into consideration, we present some suggestions for teachers, designers of educational technology systems, and policy makers.

First of all, teachers need training in both instructional methods for customized learner-centered instruction and the use of a new technology system. In addition, they need to be given more time to develop instruction and tests during their first year of using a new system. Since educational technology systems such as Moodle are relatively unfamiliar systems that change rapidly, teachers need more time and resources to learn how to use them. Previous research showed that classroom teachers believe they do not have enough time to learn and use educational technology (Ertmer, Addison, Lane, Ross, \& Woods, 1999). Our data support this research finding. Clint stated 
he knew that some of his colleagues did not want to use Moodle because it took too much time to learn. Michael mentioned, "I just began to touch the surface, and I think that there are so many things that can be done using Moodle, but learning them is time-consuming." (April 2009).

Moreover, our interviews with the teachers illustrate that most of the teachers had difficulties in accomplishing some of their activities using Moodle, since they did not have enough knowledge of the features. For example, Joshua stated an important point regarding his lack of knowledge about Moodle's features:

As what I am using, I think, it will be great if I know all features available. I haven't played around a lot yet. I am trying to know what's going on and adapt it. I don't know what are available yet. I think there are a lot of things I don't know about yet. (Joshua, April 2009)

In addition, Michael stated that he wanted to use wikis; however, he could not use this feature of Moodle because he did not know how to use it. These comments show that teachers need some training or workshops. These could be organized either by the district technology coordinator or by collaboration between technology system designers and schools.

Second, software designers need to design their systems so that they are easier to learn and use, and they need to incorporate more PIES functions into their systems. Usability is one of the main issues that can attract more teachers to use technology systems such as PIES. From the interviews, a number of the teachers pointed out that some features of Moodle are difficult to use. For instance, Laurie stated, "It would be better if it is easier to use. For example, the lesson function is hard to understand." (April 2009). In addition to Laurie, Clint also complained about the difficulty of use related to the interface:

I think that editing text is too difficult and it takes too long. As a teacher, I need to be sensitive on ease and speed. It takes a long time to edit. If this is improved, that would be nice.... It takes 10 times more time to prepare tests in Moodle. It is too bad. (Clint, April 2009)

Incorporating features that make PIES easier to learn and use would facilitate teachers' use of PIES in their instruction and eventually, facilitate the students' use as well.

Other than designing features that are easier to learn and use, technology system designers should also incorporate a greater number of functions into their system. The biggest issue might be system interoperability. Currently, teachers use multiple systems for reasons including past contracts for systems. This environment actually hinders teachers from investing more time to develop information-age paradigm instruction, since they need to spend relatively more time to learn and deal with the various systems.

Finally, policymakers need to change policies so that they support customized, learner-centered instruction, provide funding for technology systems and teacher training, and give teachers additional time during their first year of using a new system so that they can develop appropriate instruction and tests for use on it. Policymakers should work closely with technology system 
designers and teachers in order to create a more effective environment for using technology systems. For example, by providing funding, they could provide workshops for teachers on how to use technology systems to implement instructional strategies based on the information-age paradigm. Teachers should also work closely with technology system designers to provide constructive and formative feedback for designers so that they can create new features or modify existing ones. Moreover, since a lack of time is one of the biggest constraints preventing teachers from using PIES, a policy that gives teachers who are using a new technology system for the first year more time to get accustomed to it and to create instruction would be a useful intervention to promote PIES. In addition, local policymakers could create an official place, either physical or virtual, for teachers to share their knowledge of PIES and to assist each other in using PIES.

\section{Limitations}

This study was a case-study conducted in only one school district. Although the teachers represented three different schools, many different grade levels, and several different subject areas, there are some limitations due to the nature of the study. First of all, the teachers were all from one school district in a relatively homogeneous small city. Second, the teachers were those who used Moodle the most in their schools and therefore were purposely not representative of all teachers in their schools. A third limitation of this study is the absence of teachers from some content areas, such as science and art. Fourth, the schools were high schools only: the study included neither elementary nor middle schools. Finally, this study focused primarily on use of Moodle, which may be quite different from other technology systems.

\section{Conclusion}

Research findings suggest that there were discrepancies between the current use of technology systems and the identified functions of PIES in the information age. None of the seven teachers utilized Moodle for keeping students' personalized records. There was also no evidence that Moodle was being utilized for creating and storing a customized learning plan for each individual student. The interviews with the teachers indicated that the standardized education system discouraged teachers from setting individualized learning goals, and that they could not locate enough features that supported individualized learning in Moodle. Although the teachers frequently used Moodle for sharing resources and instruction, and utilized discussion forum, chatting, and glossary features for instructional purposes, evidence of project support and instructional development was scarce or non-existent. The quiz function was frequently used to formatively assess students' knowledge, but the means of assessing students' knowledge was significantly different from the information-age learning paradigm. Moodle was partially used for secondary functions of PIES. General student data and school personnel data were kept in Moodle for documentation. Instead of Moodle, Skyward was used for one-way communication with students and parents, and email was used for two-way communication.

In addition, it was found that the teachers used different types of technologies for different tasks. This was mainly because of the teachers' preferences and the schools' policies regarding the use of technology systems. The teachers had to use what the school district required, but when they had 
the freedom to choose, they used more familiar technologies. Also, teachers in different subject areas used different kinds of technologies. They identified useful features based on the characteristics of their subject content and utilized those functions. For example, an American studies teacher and a Japanese / ENL teacher frequently used the discussion forum and chatting functions. On the other hand, math and technology teachers found those functions irrelevant to their subject areas, and instead used other features that could be easily adapted to their subjects, such as the quiz function.

Based on these findings, we have made suggestions to teachers, technology system designers, and policymakers. Teachers need training in both the use of a new technology system and in instructional methods for customized, learner-centered instruction. They should also be provided with more time to develop instruction and tests during their first year of using a new system.

In order to facilitate teachers' uses of a technology system, technology system designers should make their systems easier to learn and use, add interoperability features with other technology systems, and incorporate more functions into their system that are tailored to various subject areas. Educational policymakers need to find a way to better facilitate and support the customized, learner-centered educational paradigm, including providing funding for technology systems and teacher training, and letting teachers devote additional time to developing customized instruction and assessments.

\section{References}

Aslan, S. \& Reigeluth, C. M. (2011). A trip to the past and future of educational computing: Understanding its evolution. Contemporary Educational Technology. 2(1), 1-17.

Bloom, B. S. (1968). Learning for mastery. Evaluation Comment, 1(1), 1-12.

Collins, A. \& Halverson, R. (2009). Rethinking education in the age of technology: The digital revolution and the schools. New York: Teachers College Press.

Davis, D. \& Sorrell, J. (1995). Mastery learning in public schools. Retrieved October 20, 2010, from http://www.edpsycinteractive.org/files/mastlear.html

Duffy, F. M. (2009). The need for systemic transformational change in school districts (Part 1). Retrieved 3 November 2010 from http://cnx.org/content/m19579/latest/

Ertmer, P. A., Addison, P., Lane, M., Ross, E., \& Woods, D. (1999). Examining teachers' beliefs about the role of technology in the elementary classroom. Journal of Research on Computing in Education, 32(1), 54-72.

Gilhooly, K. (2001). Making e-learning effective. Computerworld, 35(29), 52-53.

Knight, P. T. (2001). A briefing on key concepts: Formative and summative, criterion and normreferenced assessment. York, England: LTSN.

Marshall, M. N. (1996). Sampling for qualitative research. Family Practice, 13(6), 522-525. 
Reigeluth, C. M. (1995). Educational systems development and its relationship to ISD. In G. J. Anglin (Ed.), Instructional technology: Past, present, and future (2nd ed., pp. 84-93). Englewood, CO: Libraries Unlimited.

Reigeluth, C.M., Watson, W.R., Watson, S.L., Dutta, P., Chen, Z., \& Powell, N.D.P. (2008). Roles for technology in the information-age paradigm of education: Learning management systems. Educational Technology, 48(6), 32-39.

Skyward. (n.d.). In Wikipedia. Retrieved May 3, 2010, from http://en.wikipedia.org/wiki/Skyward

Smith, C. W. (1973). Criterion-referenced assessment. Paper presented at the International Symposium on Educational Testing. The Hague, The Netherlands.

Thomas, J.W. (2000). A review of research on project-based learning. San Rafael, CA: Autodesk Foundation.

Toffler, A. (1980). The third wave. New York: Morrow.

Toffler, A. (1990), Powershift: Knowledge, wealth and violence at the edge of the $21^{\text {st }}$ century, New York: Bantam Books.

Watson, W. R., Lee, S., \& Reigeluth, C. M. (2007). Learning management systems: An overview and roadmap of the systemic application of computers to education. In F. M. M. Neto \& F. V. Brasileiro (Eds.), Advances in computer-supported learning (pp. 66-96). London: Information Science Publishing.

Correspondence: Charles M. Reigeluth, Professor, Instructional Systems Technology, School of Education, Indiana University, Bloomington, IN 47405, United States. 


\section{Appendix - A: Interview \& Observation Information Sheet}

\section{In-Depth Interview Recording Sheet for Teachers}

\begin{tabular}{|l|l|}
\hline Question & 1. How do you typically use this PIES? Please demonstrate. \\
\hline Transcription & \\
\hline Comment & \\
\hline
\end{tabular}

\begin{tabular}{|l|l|}
\hline Question & $\begin{array}{l}\text { 2. Could you describe how you use PIES to accomplish adaptive sequencing and } \\
\text { adaptive lesson plans? }\end{array}$ \\
\hline Transcription & \\
\hline Comment & \\
\hline
\end{tabular}

\begin{tabular}{|l|l|}
\hline Question & 3. Could you describe how you use PIES to customize instructional content? \\
\hline Transcription & \\
\hline Comment & \\
\hline
\end{tabular}

\begin{tabular}{|l|l|}
\hline Question & $\begin{array}{l}\text { 4. Could you describe how you use PIES to set learning goals for individual } \\
\text { students? }\end{array}$ \\
\hline Transcription & \\
\hline Comment & \\
\hline
\end{tabular}

\begin{tabular}{|l|l|}
\hline Question & $\begin{array}{l}\text { 5. Could you describe how you use PIES to get specification of student, parent, } \\
\text { and teacher role for individual learning projects? }\end{array}$ \\
\hline Transcription & \\
\hline Comment & \\
\hline
\end{tabular}

\begin{tabular}{|l|l|}
\hline Question & $\begin{array}{l}\text { 6. Could you describe how you use PIES to create Post test/Pre test/Formative } \\
\text { test/Practice test/Diagnostic test? }\end{array}$ \\
\hline Transcription & \\
\hline Comment & \\
\hline
\end{tabular}

\begin{tabular}{|l|l|}
\hline Question & 7. Could you describe how you use PIES to create and manage discussion board? \\
\hline Transcription & \\
\hline Comment & \\
\hline
\end{tabular}

\begin{tabular}{|l|l|}
\hline Question & $\begin{array}{l}\text { 8. Could you describe how you use PIES to send student information report to } \\
\text { parents? }\end{array}$ \\
\hline Transcription & \\
\hline Comment & \\
\hline
\end{tabular}

\begin{tabular}{|l|l|}
\hline Question & 9. Are there any other features of the PIES that are supportive of your teaching? \\
\hline Transcription & \\
\hline
\end{tabular}




\begin{tabular}{l}
\hline Comment \\
\begin{tabular}{|l|l|}
\hline Question & $\begin{array}{l}\text { 10. [For each function or sub-function identified above] How effectively does the } \\
\text { PIES provide this function? How could it be improved? }\end{array}$ \\
\hline Transcription & \\
\hline Comment & \\
\hline
\end{tabular}
\end{tabular}

\begin{tabular}{|l|l|}
\hline Question & 11. Are there any other features you wish this PIES had? \\
\hline Transcription & \\
\hline Comment & \\
\hline
\end{tabular}

\begin{tabular}{|l|l|}
\hline Question & 12. How has the use of the PIES changed your role as a teacher? \\
\hline Transcription & \\
\hline Comment & \\
\hline
\end{tabular}

\begin{tabular}{|l|l|}
\hline Question & 13. How have students responded to the PIES? \\
\hline Transcription & \\
\hline Comment & \\
\hline
\end{tabular}

\begin{tabular}{|l|l|}
\hline Question & 14. Overall have you seen improvements in students' learning? How? \\
\hline Transcription & \\
\hline Comment & \\
\hline
\end{tabular}




\section{Appendix - B: Interview Data Coding Sheet}

\begin{tabular}{|c|c|c|c|}
\hline Name of the & & Name of the coder: & \\
\hline & & Evidence & Dis-evidence \\
\hline \multirow[t]{3}{*}{ 1.Record keeping } & 1. Standards inventory & & \\
\hline & $\begin{array}{l}\text { 2. Personal attainments } \\
\text { inventory }\end{array}$ & & \\
\hline & $\begin{array}{l}\text { 3. Personal characteristics } \\
\text { inventory }\end{array}$ & & \\
\hline \multirow[t]{7}{*}{ 2.Planning } & 1. Long-term goals & & \\
\hline & 2. Current options & & \\
\hline & 3. Short-term goals & & \\
\hline & 4. Projects & & \\
\hline & 5. Teams & & \\
\hline & 6. Roles & & \\
\hline & 7. Contracts & & \\
\hline \multirow[t]{4}{*}{ 3. Instruction } & 1. Project Initiation & & \\
\hline & 2. Instruction & & \\
\hline & 3. Project support & & \\
\hline & $\begin{array}{l}\text { 4. Instructional } \\
\text { development }\end{array}$ & & \\
\hline \multirow[t]{6}{*}{ 4. Assessment } & $\begin{array}{l}\text { 1. Presenting authentic } \\
\text { tasks }\end{array}$ & & \\
\hline & $\begin{array}{l}\text { 2. Evaluating student } \\
\text { performances }\end{array}$ & & \\
\hline & $\begin{array}{l}\text { 3. Providing immediate } \\
\text { feedback }\end{array}$ & & \\
\hline & 4. Certification & & \\
\hline & $\begin{array}{l}\text { 5. Developing student } \\
\text { assessments }\end{array}$ & & \\
\hline & $\begin{array}{l}\text { 6. Improving } \\
\text { instruction/assessment }\end{array}$ & & \\
\hline \multirow[t]{4}{*}{ 5. Secondary } & 1. Communication & & \\
\hline & 2. General student data & & \\
\hline & $\begin{array}{l}\text { 3. School personnel } \\
\text { information }\end{array}$ & & \\
\hline & 4. LMS administration & & \\
\hline \multicolumn{4}{|l|}{$\begin{array}{l}\text { Teachers' } \\
\text { suggestions }\end{array}$} \\
\hline Other themes & & & \\
\hline
\end{tabular}

